\title{
Interação oral em língua espanhola: uma proposta de imersão comunicativa e tecnológica para estudantes de cursos livres
}

\author{
Iandra Maria Weirich da Silva Coelho ${ }^{1}$ \\ Franciane de Araújo Soares ${ }^{2}$
}

\begin{abstract}
RESUMO
Este artigo apresenta uma proposta para avaliar a interação oral, no contexto de ensino-aprendizagem de Língua Espanhola (LE). Dada à dificuldade de professores em avaliar essa habilidade comunicativa, especialmente na modalidade de Cursos Livres, oferecidos em instituições de ensino brasileiras, foi desenvolvida uma proposta estruturada em três fases: compilação de uma Matriz de descritores para avaliar a interação oral em LE; elaboração de uma atividade didática, com ênfase na imersão comunicativa e tecnológica e construção de uma rubrica para autoavaliação. Os procedimentos metodológicos compreendem uma revisão bibliográfica e análise por meio de um Estudo de Caso, realizado com estudantes de espanhol, de nível intermediário, com o objetivo de identificar as principais contribuições e limitações encontradas. Os resultados indicam que a proposta contribuiu para fomentar a autoavaliação do próprio aprendizado e possibilitar a identificação dos níveis de desempenho, evidenciando a fluência e a pronúncia como os critérios de maior dificuldade para os estudantes.
\end{abstract}

PALAVRAS-CHAVE: Tecnologia educacional. Ensino-aprendizagem. Avaliação. Competência comunicativa. Cursos de línguas.

Oral interaction in spanish language: a proposal of communicative and technological immersion for students of open language courses

\footnotetext{
1 Doutora em Linguística. Universidade Federal de Santa Catarina, Santa Catarina, Paraná, Brasil. https://orcid.org/0000-0003-3513-962X.iandrawcoelho@gmail.com.

2 Mestra em Ensino Tecnológico. Instituto Federal de Educação Ciência e Tecnologia do Amazonas, Manaus, Amazonas, Brasil. https://orcid.org/0000-0002-7993-4388.franciane.soares@gmail.com.
} 


\begin{abstract}
This paper presents a proposal to evaluate oral interaction in the context of Spanish language teaching and learning. Given this difficulty of teachers to evaluate this communicative ability, especially in Open language courses modality, offered in Brazilian educational institutions, a structured proposal was developed in three phases: compilation of a descriptors Matrix for assess the oral interaction in LE; elaboration of a didactic activity focused on communicative and technological immersion and building a rubric for self-evaluation. The methodological procedures consist in a bibliographic review and analysis through a case study conducted on students of an intermediate level of Spanish language, aiming to identify the main contributions and limitations found. The results indicate that the proposal contributed to foster self-assessment of learning itself and enable the identification of performance levels, evidencing fluency and pronunciation as the most difficult criteria for students.
\end{abstract}

KEYWORDS: Educational technology. Teaching, evaluation. Communicative competence. Language courses.

Interacción oral en lengua española: una propuesta de inmersión comunicativa y tecnológica para estudiantes de cursos libres

\title{
RESUMEN
}

Este artículo presenta una propuesta para evaluar la interacción oral, en el contexto de la enseñanza-aprendizaje de la Lengua Española (LE). Dada la dificultad de profesores en evaluar esa habilidad comunicativa, especialmente en la modalidad de Cursos Libres, ofrecidos en instituciones de enseñanza brasileñas, se desarrolló una propuesta estructurada en tres fases: compilación de una Matriz de descriptores para evaluar la interacción oral en LE; elaboración de una actividad didáctica, con énfasis en la inmersión comunicativa y tecnológica y construcción de una rúbrica para autoevaluación. Los procedimientos metodológicos comprenden una revisión bibliográfica y análisis por medio de un Estudio de Caso, realizado con estudiantes de español, de nivel intermedio, con el objetivo de identificar las principales contribuciones y limitaciones encontradas. Los resultados indican que la propuesta contribuyó a fomentar la 
autoevaluación del propio aprendizaje y posibilitar la identificación de los niveles de desempeño, evidenciando la fluidez y la pronunciación como los criterios de mayor dificultad para los estudiantes.

PALABRAS CLAVE: Tecnología Educativa. Enseñanza-evaluación. Competencia comunicativa. Cursos de idiomas.

$$
* * *
$$

\section{Introdução}

A aprendizagem de diferentes línguas, no atual contexto sociohistórico, é uma necessidade, devido ao desenvolvimento econômico e cultural alcançado pelas sociedades. Esse aprendizado possibilita ver e compreender o mundo de uma nova maneira (ECKERT; FROSI, 2015), ampliando as possibilidades de aprendizagem e de fomento ao senso crítico e autonomia.

No âmbito educacional, essa realidade linguística leva em conta, tanto o domínio da língua materna, como o desenvolvimento da competência comunicativa em outras línguas, permitindo a atuação em distintas situações, presenciais e virtuais. Nesse contexto, o ato de comunicar é considerado uma competência fundamental (MONTEIRO et al., 2013) que tem a língua oral como um veículo para potencializar as relações sociais, internacionais, profissionais e de negócios.

Entre as implicações pedagógicas relacionadas ao desenvolvimento da competência comunicativa, no contexto de ensino-aprendizagem de línguas, destacamos o processo de avaliação, um assunto complexo, em que coexistem aspectos que podem ser considerados subjetivos ou imprecisos, tais como, o nervosismo dos estudantes e o cansaço dos ouvintes/interlocutores (BARQUERO DÁVANZO; UREÑA SALAZAR, 2015) e que necessitam ser amplamente discutidos.

Para Jetté (2017), avaliar a oralidade não é uma tarefa simples, muito menos quando se trata de avaliar a interação oral, devido à complexidade do processo, até mesmo para os professores mais experientes. Ainda que a 
oralidade seja trabalhada de diferentes maneiras durante as aulas de línguas, considera-se difícil sistematizá-la, devido à dificuldade em definir critérios para mensurar o desenvolvimento da competência oral, especialmente a interação na língua-alvo que envolve outros processos, como a compreensão e a produção oral (SILVA, 2018).

Essa constatação é um reflexo das lacunas existentes com relação às práticas avaliativas docentes, como por exemplo, no ensino da Língua Espanhola (doravante LE), especialmente em contextos de cursos de extensão e na modalidade de Cursos Livres, oferecidos em instituições de ensino brasileiras, cenário em que se efetivam as experiências docentes das autoras. Entre as implicações pedagógicas e dificuldades que circundam o processo de ensino-aprendizagem, destaca-se a avaliação da competência comunicativa na língua e a certificação dos estudantes, de acordo com os níveis de proficiência alcançados.

A partir desse cenário exposto, surge a necessidade de elaborar novas propostas que possam auxiliar o trabalho docente, suscitando a questão norteadora dessa pesquisa: Como podemos avaliar o desempenho de estudantes de Língua Espanhola na habilidade de interação oral, considerando o contexto de ensino em cursos livres e extracurriculares? Nesse sentido, temos como objetivo principal, desenvolver uma proposta avaliativa e a partir de sua implementação e análise, verificar as principais contribuições e limitações encontradas.

Para tanto, desenvolvemos uma proposta para avaliar a interação oral em LE, pautada em três etapas: compilação de uma Matriz de descritores para avaliação da interação oral em LE que compreende descritores e níveis de proficiência; elaboração de uma atividade didática, com ênfase na imersão comunicativa e tecnológica e construção de uma rubrica de (auto)avaliação, com base em critérios, descritores e níveis de proficiência, previamente adotados, para auxiliar na identificação dos progressos e dificuldades dos estudantes e fomentar a participação ativa do aprendiz no processo de avaliação e reflexão acerca dos desempenhos alcançados. 
Essa proposta foi desenvolvida e implementada com o uso de diferentes recursos tecnológicos para a realização de uma atividade comunicativa híbrida que mistura o presencial e o virtual, e é simulada por meio de uma entrevista via webconferência, com uma proposta de imersão na língua, no contexto comunicativo e tecnológico.

Os procedimentos metodológicos envolveram a revisão bibliográfica da literatura pertinente, realizada com base na temática abordada, em que evidenciamos estudos sobre a avaliação da interação oral na língua-alvo (ESCOBAR; NUSSBAUM, 2010; MORAL MANZANARES, 2013; JETTÉ, 2017), a competência comunicativa (HYMES, 1972; CONSELHO DA EUROPA, 2001); e o uso de rubricas para a avaliação (MARTÍNEZ-ROJAS, 2008; BARQUERO DÁVANZO, UREÑA SALAZAR, 2015; MENDONÇA; COELHO, 2018).

Além disso, a metodologia compreendeu a aplicação e análise dessa proposta, realizada recorrendo ao método de Estudo de Caso (YIN, 2015). A coleta de dados foi realizada por meio de um questionário e a análise, de abordagem quantitativa e qualitativa, conta com o auxílio do software de pesquisa Sphinx Léxica. O público-alvo investigado compreendeu uma turma de estudantes de espanhol, de nível intermediário, do Centro de Idiomas, do Instituto Federal de Educação, Ciência e Tecnologia do Amazonas.

\section{A interação oral e os processos de ensino, aprendizagem e avaliação da LE}

Neste estudo, o termo interação oral abrange os processos primários de produção e compreensão oral (CONSELHO DA EUROPA, 2001), as condições socioculturais do contexto envolvido ou simulado, bem como as atitudes necessárias para uma atuação oral que possibilite a comunicação em diferentes contextos, legitimando o uso comunicativo da língua.

O desenvolvimento da interação oral visa à busca pela melhoria da competência comunicativa em diferentes contextos linguísticos e culturais, 
com foco nas necessidades de comunicação. Esse processo leva em conta aspectos sociais, bem como a relação entre o comunicador e o interlocutor, uma vez que a comunicação conduz a maior mobilidade, favorece o intercâmbio, estimula a compreensão recíproca e reforça a colaboração (CONSELHO DA EUROPA, 2001).

A interação está relacionada diretamente à competência pragmática, levando em conta o uso funcional dos recursos linguísticos (produção de funções linguísticas, atos de fala), bem como o domínio do discurso, da coesão e da coerência, a identificação de tipos e formas de texto, a ironia etc. (CONSELHO DA EUROPA, 2001).

Tendo em conta que a comunicação é um processo que depende do contexto social, e se reconhece a interdependência desses dois aspectos, o processo de aprendizagem de uma língua adicional envolve metodologias apropriadas e a aplicação de estratégias didáticas que facilitam ao aprendiz o desenvolvimento de suas habilidades linguísticas, sociolinguísticas e pragmáticas, de acordo com suas necessidades comunicativas.

Nesse processo, é importante haver uma definição clara dos conteúdos interacionais ensinados e avaliados, levando em conta o impacto positivo de um modelo de avaliação que considera o processo comunicativo (JETTÉ, 2017). Dessa forma, consideramos a criação de uma proposta avaliativa à luz de três dimensões: comunicativa, cognitiva e sociocultural (ROMÉU ESCOBAR et al., 2007), tendo em vista o processo de ensino-aprendizagem de línguas como resultado da tríade formada por discurso, cognição e sociedade, com base nos processos cognitivos e comunicativos, que acontecem nas situações sociais de comunicação, em diferentes contextos culturais. Além da dimensão comunicativa, levamos em conta também o contexto de imersão tecnológica, com ênfase no uso de diferentes recursos digitais.

Isso implica promover novas práticas que possam auxiliar os professores na avaliação das habilidades comunicativas dos estudantes, especialmente voltados para a melhoria do processo de ensino-aprendizagem em Cursos Livres, uma modalidade que cresce no Brasil, devido à criação e 
expansão de centros de idiomas, núcleos de línguas ou estruturas congêneres, pertencentes às universidades brasileiras, instituições da Rede Federal de Educação Profissional, Científica e Tecnológica e algumas Secretarias de Educação. Esses espaços formativos auxiliam na democratização de oferta de cursos para melhorar a competência linguística dos membros da comunidade universitária e da comunidade em geral, tendo em vista a preocupação com o ensino-aprendizagem das línguas, a promoção do plurilinguismo e o fomento à internacionalização das instituições federais de ensino.

As atuais necessidades e demandas com relação ao desenvolvimento da competência comunicativa em outras línguas, nas instituições de ensino, refletem a importância do papel desses espaços formativos visando à democratização do acesso às línguas adicionais (COELHO; TEIXEIRA, 2020). De acordo com Freire ${ }^{3}$ (2020), "esses centros têm um duplo papel. Ao mesmo tempo que pluralizam a oferta de línguas à comunidade, trazem essa comunidade de volta ao espaço público do ensino de línguas, reconstruindo uma relação fundamental" (COELHO; TEIXEIRA, 2020).

De acordo com Freitas (2010, p.1), na atualidade, "a principal demanda é de jovens e adultos que desejam aprender o idioma para utilizá-lo em suas atividades profissionais ou de estudantes universitários que querem preparar-se para o mercado de trabalho”. Segundo a autora, nessas condições, esse público procura por cursos livres de línguas, pois já se encontra fora do ambiente escolar. Ainda no caso de estudantes universitários, são poucas as graduações que ofertam a Língua Espanhola nas suas grades, tornando-se clientes potenciais para os cursos livres, desde uma perspectiva extensionista.

Segundo Freitas e Souza (2018, p.32), os cursos livres são "instituições que não se encontram no âmbito de controle dos organismos estatais da educação”, no entanto, há um fomento das iniciativas governamentais para que essas instituições sejam responsáveis pelo ensino de línguas, produção de materiais didáticos e/ou formação continuada docente em escolas públicas de

\footnotetext{
${ }^{3}$ Prefácio em Coelho e Teixeira (2020).
} 
Educação Básica. Alguns exemplos dessas situações estão presentes nos âmbitos: federal, estadual e municipal.

Avaliar a interação oral em LE nessa modalidade implica na necessidade em contribuir para a aprendizagem e desenvolvimento de competências necessárias para a proficiência na língua, em especial, a competência conversacional, considerando que a avaliação é uma operação que não se dissocia do processo e pode potencializar a internalização e comprovação dos conhecimentos linguísticos (CABRERA, JARA; GÓMEZ, 2013).

Nesse sentido, ressaltamos a importância da coleta e análise das inferências sobre um determinado critério (comportamento comunicativo); a relevância do uso de instrumentos para avaliar esses critérios; e o potencial das simulações, já que essas estratégias expõem os estudantes a situações comunicativas que podem ocorrer na vida real e, portanto, podem ser utilizadas no processo de avaliação da língua-alvo.

Esses aspectos levam em conta a necessidade de avaliar a proficiência de um estudante, que pode ser realizada, a partir de atividades comunicativas que permitem ao estudante demonstrar a proficiência na língua e a sua capacidade de interação. Para isso, é importante simular situações reais de conversação. Nesse cenário, as simulações podem contribuir para consolidar novas propostas com foco na competência oral na língua-alvo, por meio de interações que podem ser potencializadas dentro e fora do contexto formal de sala de aula. Essas interações são relevantes e necessárias, considerando que apesar da ênfase dada ao desenvolvimento das quatro habilidades, no âmbito escolar, o desempenho oral dos estudantes, em diferentes cenários, não é compatível com os resultados pretendidos de proficiência.

Nesse contexto, a utilização de instrumentos também pode apresentar outros tipos de desafios para a avaliação das habilidades orais (JETTÉ, 2017). O domínio dessas habilidades pode ser avaliado por diferentes instrumentos (PANTOJA, 2012), tendo em vista a necessidade de mensurar e atribuir notas. 
Levando em conta a subjetividade do processo de avaliação da produção oral (QUEVEDO-CAMARGO; GARCÍA, 2017), é necessário selecionar instrumentos que permitam viabilizar medidas que possam reduzir alguns efeitos dessa natureza subjetiva da avaliação da produção oral.

Entre esses instrumentos, destacamos as rubricas, optando por uma avaliação mediada por critérios pré-estabelecidos. De acordo com Brookhart (2013 citado em MENDONÇA; COELHO, 2018, p.109), "uma rubrica é um conjunto coerente de critérios sobre o trabalho a ser realizado pelo estudante que inclui descrições de níveis de desempenho (performance)". Por meio dessa ferramenta, é possível evidenciar dimensões que compõem uma situação ou atividade a ser resolvida; permitir que os estudantes direcionem seus esforços para a obtenção de níveis mais altos de proficiência na língua; potencializar os processos cognitivos e de autorregulação, na medida em que assumem uma postura crítica, em relação à avaliação do próprio progresso na aprendizagem da língua, bem como direcionar os esforços para alcançar o desempenho desejado.

A justificativa para a criação de rubricas deve-se à "busca de procedimentos avaliativos justos, equitativos, válidos e transparentes, com propósitos formativos e por princípios democráticos" (PICÓN-JÁCOME, 2013 apud MENDONÇA; COELHO, 2018, p.109). Esse tipo de avaliação é evidenciado por autores como um novo paradigma de cunho positivo para a educação.

\section{Método}

Em decorrência do objetivo dessa pesquisa ${ }^{4}$, de abordagem descritiva, utiliza-se o método de Estudo de Caso, com foco na compreensão de um caso em profundidade, nas múltiplas fontes de coletas de dados e na análise do

\footnotetext{
${ }^{4}$ A pesquisa foi aprovada pelo Comitê de Ética, do Instituto Federal de Educação, Ciência e Tecnologia do Amazonas, sob n. 92902718.0.0000.8119.
} 
caso por meio da descrição do tema, desde uma perspectiva qualitativa (YIN, 2015).

Por outro lado, desde uma perspectiva quantitativa, utilizamos um questionário, como técnica para coleta dos dados, a fim de evidenciar as principais contribuições e limitações da proposta avaliativa, com base na experiência vivenciada pelos estudantes na avaliação. Essa análise da proposta foi realizada por estudantes de um curso de Língua Espanhola, de nível intermediário, do Centro de Idiomas, do Instituto Federal do Amazonas e professor da turma.

A etapa inicial da pesquisa compreendeu uma pesquisa bibliográfica, para a definição do construto teórico, tendo em conta diferentes bases de consulta: Scielo, Repositórios Científicos de Acesso Aberto de Portugal (RCAAP), Biblioteca Digital Brasileira de Teses e Dissertações (BDBTD), Dialnet e Google Acadêmico.

Os procedimentos metodológicos também envolvem o desenho teóricometodológico da proposta avaliativa que compreendeu três etapas: a fase de planejamento, que envolveu a compilação de uma Matriz de descritores para avaliação da interação oral em LE; a criação de uma atividade comunicativa para desenvolvimento da interação oral em LE e a elaboração de uma rubrica e validação da proposta.

O processo de validação da proposta foi realizado por um comitê de juízes, formado por especialistas de diferentes instituições do país. A função do comitê foi avaliar os elementos que compõem a rubrica (critérios, descritores e níveis), e a atividade. Em síntese, a avaliação teve como foco uma análise relacionada à pertinência (relevância e representatividade) e à clareza (inteligível pelo leitor) de cada item, consideradas aspectos fundamentais para a construção de instrumentos avaliativos (CRESTANI, MORAES; SOUZA, 2017).

Com base nos resultados dessa valoração, foram realizadas mudanças no instrumento, a fim de determinar a permanência ou exclusão dos itens. As considerações do comitê avaliador permitiram realizar: i) correções textuais, 
a fim de melhorar a clareza dos itens analisados; ii) exclusão de itens; e iii) inclusão de novos descritores.

A aplicação da proposta contou com uso de dois laboratórios de línguas e diferentes ferramentas: computadores, plataforma Google Classroom; WhatsApp; plataforma de mensagens instantâneas e chat de vídeo hangouts; webcam, microfone para interação; câmera para gravação de vídeo; fone de ouvido, caixa de som, data show, quadro branco e uma rubrica impressa para (auto)avaliação.

Entre as estratégias utilizadas durante a aplicação, destaca-se a gravação de um vídeo que foi enviado aos estudantes, por e-mail, com as interações, para que pudessem analisar as falas e identificar as principais falhas, com relação aos critérios avaliados. Essa ação também permitiu ao professor rever a avaliação dos estudantes.

\section{Desenho teórico-metodológico da proposta avaliativa}

A elaboração da proposta para avaliar a interação oral em LE compreendeu três fases (Figura 1). A primeira trata da compilação de uma Matriz de descritores para avaliação da interação oral em LE, organizada de acordo com as habilidades linguísticas da língua - compreensão, produção e interação oral (CONSELHO DA EUROPA, 2001) e estruturada de acordo com os níveis de desempenho dos estudantes, com base nas escalas de proficiência, utilizadas em certificações oficiais. A segunda trata da elaboração de uma atividade que compreende o uso de recursos tecnológicos para o desenvolvimento da interação oral em LE. A terceira apresenta a criação de uma rubrica para avaliar a interação oral em LE. 
FIGURA 1. Composição da proposta avaliativa.

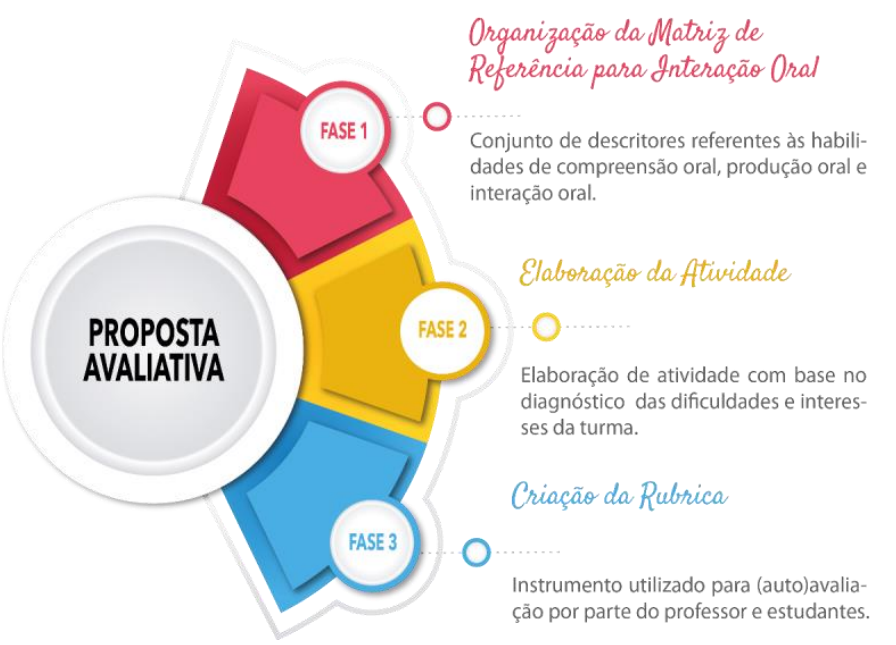

Fonte: Adaptado de Soares e Coelho (2019).

A Matriz compreende um conjunto de descritores organizados por atividades linguísticas e níveis, e compõe um banco de descritores para avaliar a interação oral em LE. Tais descritores são oriundos do Quadro Europeu Comum de Referência para as línguas (QECR), das certificações internacionais da língua (DELE, CELU, SIELE) e dos parâmetros para exames de línguas desenvolvidos pela Associação de Examinadores de Língua na Europa (ALTE). Tem como objetivo ser utilizada como uma ferramenta para auxiliar na elaboração de atividades comunicativas, bem como, planejamento e elaboração de instrumentos avaliativos, uma vez que possibilita ao professor a identificação dos elementos necessários, levando em conta a proficiência comunicativa na língua.

A atividade foi desenvolvida a partir de um diagnóstico realizado com os alunos para verificar quais as principais dificuldades encontradas com relação ao uso da língua. De acordo com esses resultados, os estudantes evidenciaram como principal dificuldade a "participação de uma entrevista em língua espanhola”, considerada uma atividade comunicativa para a qual não se encontravam preparados para manter uma interação oral na línguaalvo. Em virtude disso, o desenho da proposta foi idealizado em formato de entrevista. Essa estratégia é caracterizada como uma técnica para o 
desenvolvimento e avaliação da interação oral. (BORDÓN, 2008; PANTOJA, 2012).

Ilustramos a atividade para desenvolver a interação oral na língua, no Quadro 1:

\section{QUADRO 1. Proposta de atividade}

\begin{tabular}{|c|c|}
\hline Nivel & Utilizador independente (B1) \\
\hline Turma & Intermediário II - Sete (07) estudantes \\
\hline Objetivo & $\begin{array}{l}\text { Interação oral por meio de entrevista via webconferência para debate de } \\
\text { propostas de candidatos brasileiros fundamentados nos sistemas políticos } \\
\text { de países hispanos. }\end{array}$ \\
\hline Atividade & Simulação de uma entrevista por meio de webconferência. \\
\hline $\begin{array}{l}\text { Objetivos } \\
\text { específicos }\end{array}$ & $\begin{array}{l}\text { - Investigar sobre os sistemas políticos dos países hispanos; } \\
\text { - Elaborar propostas para o Brasil fundamentado na política de um país } \\
\text { (escolhido pelo estudante); } \\
\text { - Trabalhar as estruturas estudadas para entrevistar alguém, responder } \\
\text { a uma entrevista e expressar: medo ou insegurança/ desacordo ou } \\
\text { indignação com relação ao tema proposto e apresentado na interação; } \\
\text { - Trocar, verificar e confirmar informações, lidar com situações menos } \\
\text { habituais e explicar por que razão há um problema; } \\
\text { - Exprimir o que pensa sobre assuntos mais abstratos ou culturais; } \\
\text { - Abordar, sem preparação prévia, assuntos que lhe sejam familiares, } \\
\text { expressar opiniões pessoais e trocar informações sobre assuntos que lhe } \\
\text { são familiares, de interesse pessoal ou pertinentes para a vida cotidiana } \\
\text { (p. ex.: a família, os tempos livres, o trabalho, as viagens e outros } \\
\text { acontecimentos correntes). } \\
\text { - Participar de uma webconferência. }\end{array}$ \\
\hline Justificativa & $\begin{array}{l}\text { - Proporcionar aos estudantes de língua espanhola o conhecimento dos } \\
\text { sistemas políticos dos países hispanos, a fim de encontrar boas práticas } \\
\text { para solucionar os problemas vivenciados pelos brasileiros por conta da } \\
\text { má administração pública. } \\
\text { - Contextualizar o tema das eleições para evidenciar os problemas } \\
\text { enfrentados com a imigração de venezuelanos ao Brasil, com o intuito de } \\
\text { fomentar a reflexão por parte dos eleitores e busca de novas alternativas } \\
\text { para abordar essa problemática vivenciada pelo país. }\end{array}$ \\
\hline $\begin{array}{l}\text { Questões } \\
\text { norteadoras }\end{array}$ & 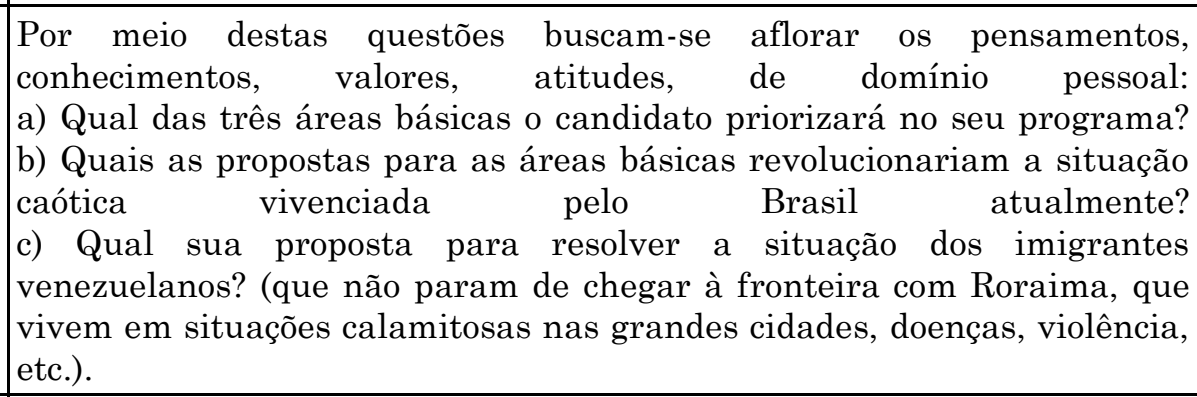 \\
\hline $\begin{array}{l}\text { Coml } \\
\text { deser }\end{array}$ & $\begin{array}{l}\text { Interação em LE por meio das TIC: o estudante mobilizará os } \\
\text { conhecimentos declarativos (saber: conhecimento de mundo, sociocultural, } \\
\text { consciência intercultural); bem como habilidades de cunho comunicativo }\end{array}$ \\
\hline
\end{tabular}




\begin{tabular}{|c|c|}
\hline & $\begin{array}{l}\text { nos contextos virtuais, simulado por meio de uma (web/vídeo) conferência } \\
\text { aliados às atitudes para aprender a língua e execução de uma tarefa. }\end{array}$ \\
\hline $\begin{array}{l}\text { Métodos para a } \\
\text { realização da } \\
\text { atividade }\end{array}$ & $\begin{array}{l}\text { Pesquisa: Entrevistas reais (contato com nativos); criação de Resumos; } \\
\text { Analogias entre os sistemas políticos estudados (Brasil x País hispano): } \\
\text { criação de propostas. }\end{array}$ \\
\hline \multicolumn{2}{|r|}{ AVALIAÇÃO } \\
\hline $\begin{array}{l}\text { Categorias } \\
\text { avaliadas }\end{array}$ & $\begin{array}{l}\text { Adequação à tarefa e coesão, Fluência e interação oral, Repertório } \\
\text { gramatical, Repertório léxico e Pronúncia. }\end{array}$ \\
\hline Recursos & Internet; Ferramentas para webconferência: celular, câmera, gravador; \\
\hline
\end{tabular}

Fonte: Adaptado de Soares (2019, p. 66-67)

A entrevista possibilita a prática de diálogos espontâneos, a troca de informação, o uso de repertório linguístico e de estruturas gramaticais, com base no tema explorado, de forma que os estudantes possam expressar opiniões. Dessa maneira, buscou-se atender aos objetivos comunicativos da língua em uma atividade de simulação de entrevista, na qual um falante nativo (participante convidado, natural do Chile, da cidade de Valparaíso), participa como entrevistador, possibilitando ao aprendiz uma experiência autêntica de interação na língua. A realização dessa dinâmica foi realizada por meio do Hangouts.

Apresentamos na Figura 2, a organização dos espaços para a aplicação da proposta avaliativa.

FIGURA 2. Divisão das estações
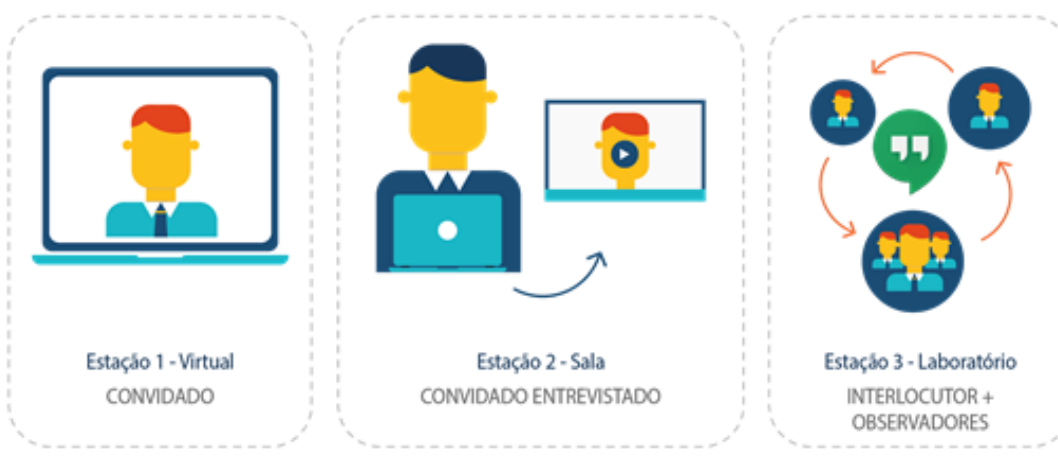

Fonte: Soares (2019, p.69) 
Foi necessário organizar o espaço, tendo em vista que a atividade acontece em um ambiente virtual, mediado por uma plataforma digital para a comunicação, por meio de áudio e vídeo. Para tanto, houve a implementação de três estações. A estação 1 representa a conexão direta com o convidado, caracterizada pelo espaço ocupado pelo nativo, por meio da plataforma Hangouts. A estação 2 foi ocupada por um estudante entrevistado que interpretou um candidato a uma entrevista. Essa estação foi organizada em uma sala reservada, com conexão ao Hangouts, destinada exclusivamente para o estudante entrevistado. A estação 3 é composta pelos demais estudantes que acompanham e participam das interações, via Hangouts.

E por fim, a construção de uma rubrica avaliativa, que foi desenvolvida levando em conta cinco critérios de análise: conteúdo, coerência e coesão, vocabulário, fluência e pronúncia. Para cada critério, foram estabelecidos um conjunto de descritores e o nível de proficiência dos estudantes, com base no QECR (Quadro 2).

QUADRO 2. Rubrica de (auto)avaliação da interação oral em LE.

\begin{tabular}{|c|c|c|c|}
\hline Critério & $\begin{array}{l}\text { A1: } \quad \text { Utilizador } \\
\text { básico (Iniciar) }\end{array}$ & $\begin{array}{c}\text { A2: Utilizador básico } \\
\text { (Elementar) }\end{array}$ & $\begin{array}{l}\text { B1: Utilizador } \\
\text { independente } \\
\text { (Limiar) }\end{array}$ \\
\hline Tema & $\begin{array}{l}\text { O conteúdo é } \\
\text { mínimo e apresenta } \\
\text { vários erros com } \\
\text { relação aos fatos. }\end{array}$ & $\begin{array}{l}\text { Consegue falar sobre o } \\
\text { tema indicado, mas não } \\
\text { contribui com novas } \\
\text { ideias. }\end{array}$ & $\begin{array}{l}\text { Cobre os temas em } \\
\text { profundidade com } \\
\text { detalhes e exemplos, } \\
\text { além de contribuir } \\
\text { com novas ideias. }\end{array}$ \\
\hline $\begin{array}{l}\text { Coerência e } \\
\text { coesão }\end{array}$ & $\begin{array}{l}\text { Elabora enunciados } \\
\text { isolados e sem } \\
\text { elementos de ligação } \\
\text { (básicos: e, então). } \\
\text { O discurso é } \\
\text { confuso, não segue } \\
\text { uma lógica na } \\
\text { apresentação das } \\
\text { ideias. }\end{array}$ & $\begin{array}{l}\text { Comunica ideias e } \\
\text { informações, desde que } \\
\text { possa ser ajudado a } \\
\text { exprimir aquilo que } \\
\text { pretende dizer. } \\
\text { Utiliza os conectores que } \\
\text { ocorrem mais } \\
\text { frequentemente (e, mas, } \\
\text { porque) para ligar frases } \\
\text { simples e contar uma } \\
\text { história ou descrever algo } \\
\text { como uma lista simples } \\
\text { de informações. }\end{array}$ & $\begin{array}{l}\text { Exprime de forma } \\
\text { articulada a ideia do } \\
\text { discurso. } \\
\text { Liga uma série de } \\
\text { elementos curtos, } \\
\text { distintos e simples } \\
\text { construindo uma } \\
\text { sequência linear. }\end{array}$ \\
\hline & 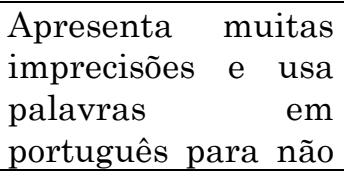 & $\begin{array}{lr}\text { Mostra } & \text { suficiente } \\
\text { controle do } & \text { vocabulário } \\
\text { necessário } & \text { para a }\end{array}$ & 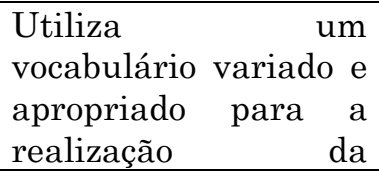 \\
\hline
\end{tabular}




\begin{tabular}{|c|c|c|c|}
\hline Vocabulário & $\begin{array}{lr}\text { afetar } & \text { a } \\
\text { comunicação. } & \\
\text { Apresenta } & \text { um } \\
\text { vocabulário } & \\
\text { reduzido expressado } \\
\text { por frases curtas. } \\
\text { Apresenta } \\
\text { excessivas } \\
\text { interferências } & \\
\text { português } & \text { do } \\
\text { repetições } & \text { de } \\
\text { vocabulário. } & \end{array}$ & $\begin{array}{l}\text { atividade utilizando-o de } \\
\text { forma correta. } \\
\text { Repetições frequentes e } \\
\text { interferências } \\
\text { português. } \\
\text { Comete erros ao tentar } \\
\text { usar vocabulário mais } \\
\text { complexo. }\end{array}$ & 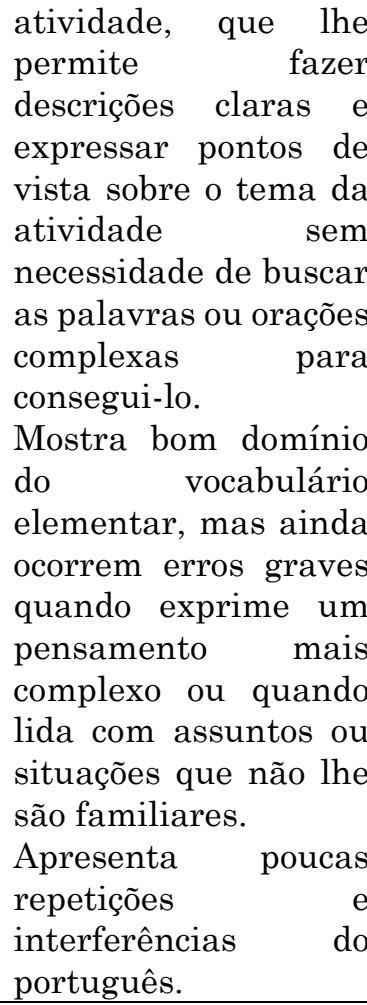 \\
\hline Fluência & $\begin{array}{l}\text { Apresenta discurso } \\
\text { em ritmo lento com } \\
\text { extensas pausas. } \\
\text { Sente dificuldades } \\
\text { para conversar ou } \\
\text { pedir } \\
\text { esclarecimentos. } \\
\text { Limita-se a } \\
\text { respostas breves e } \\
\text { muitas vezes } \\
\text { inapropriadas. }\end{array}$ & $\begin{array}{l}\text { Apresenta discurso } \\
\text { bastante fluido ainda que } \\
\text { com pausas } \\
\text { reformulações. } \\
\text { Entende as perguntas de } \\
\text { temas familiares e } \\
\text { responde } \\
\text { adequadamente sem } \\
\text { dificuldades. } \\
\text { O acento, o ritmo e a } \\
\text { entonação distanciam-se } \\
\text { da norma. }\end{array}$ & $\begin{array}{l}\text { Interage com eficácia } \\
\text { e sem ajuda, apesar de } \\
\text { alguns problemas de } \\
\text { formulação. } \\
\text { Reage rapidamente a } \\
\text { perguntas e opiniões: } \\
\text { expressa suas ideias } \\
\text { com fluência e } \\
\text { autonomia. } \\
\text { O acento, ritmo e } \\
\text { entonação aproxima- } \\
\text { se da norma. }\end{array}$ \\
\hline Pronúncia & $\begin{array}{lr}\text { Muitos erros } & \text { de } \\
\text { pronúncia } & \text { que } \\
\text { fazem que a } & \text { a } \\
\text { compreensão } & \text { seja } \\
\text { quase nula. } & \\
\text { Representa } & \text { a } \\
\text { maioria dos sons em } \\
\text { português. } \\
\text { Não corrige alguns } \\
\text { erros de pronúncia } \\
\text { mais }\end{array}$ & $\begin{array}{l}\text { A pronúncia é inteligível } \\
\text { para ser entendida, mas } \\
\text { apresenta interferências } \\
\text { dos sons do português. } \\
\text { Apresenta erros em } \\
\text { palavras de uso comum, } \\
\text { ainda que de modo geral } \\
\text { se possa entender. } \\
\text { Corrige alguns erros de } \\
\text { pronúncia. }\end{array}$ & 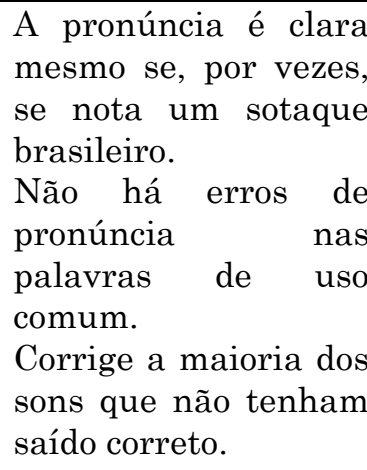 \\
\hline
\end{tabular}

Fonte: Soares (2019, p. 113-114)

\section{Resultados}


A proposta para avaliar a interação oral em LE foi composta por cinco critérios: conteúdo, coerência e coesão, vocabulário, fluência e pronúncia. Para cada critério, os estudantes e professor poderiam avaliar o desempenho na realização da atividade, com base em descritores correspondentes aos níveis A1 (Iniciante), A2 (Básico) e B1(Intermediário). Essa divisão leva em conta os níveis de desempenho evidenciados no QECR e as principais certificações internacionais para a língua espanhola (DELE, CELU, SIELE), bem como os parâmetros para exames de línguas, desenvolvidos pela Associação de Examinadores de Língua na Europa.

Ocorreram duas avaliações. Uma delas foi feita pelos alunos (Figura 3), e outra pelo professor, apresentada em seguida na Figura 4.

FIGURA 3. Resultados da autoavaliação

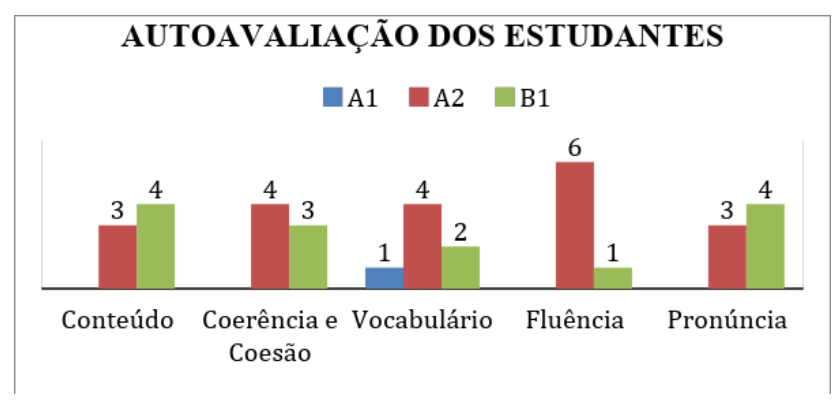

Fonte: Soares (2019, p. 80)

Cabe ressaltar que o propósito era concentrar o maior número possível de estudantes no nível Intermediário (B1), levando em conta que os estudantes que realizaram a proposta avaliativa são oriundos de um curso de línguas, de nível Intermediário. De modo geral, no que se referem aos critérios, os estudantes apontam uma autoavaliação direcionada ao nível A2. Entre os critérios avaliados, a "fluência" é o principal critério em que a maioria dos estudantes não considera atingir o nível mais alto de proficiência (intermediário).

Por outro lado, os dados da avaliação do professor apresentam resultados distintos, levando em conta a observação direta em sala de aula (Figura 4). 
FIGURA 4. Critérios avaliados pelo professor.

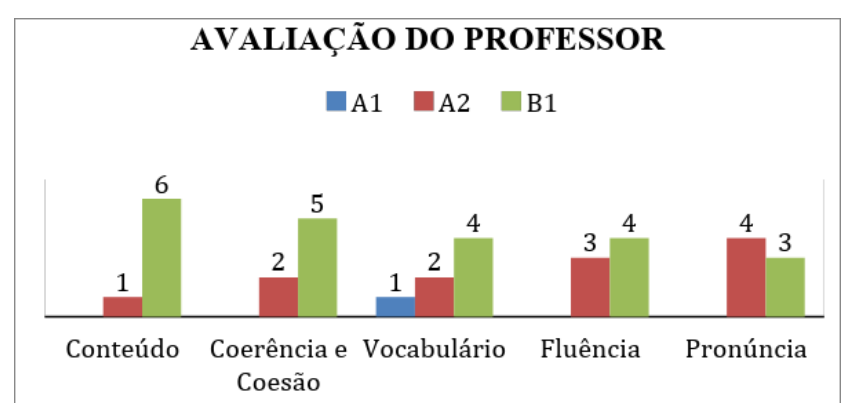

Fonte: Soares (2019, p. 80)

Nessa avaliação, identificamos que o desempenho em quatro critérios indica uma predominância do nível (B1). É possível destacar a fluência e a pronúncia como critérios que exigem maior grau de atenção e exigência, levando em conta que se trata de uma atividade de interação oral na línguaalvo. Especialmente na proposta apresentada, esses aspectos são indispensáveis, considerando a competência comunicativa oral, uma vez que a atividade é realizada com um falante nativo, o que pode exigir do estudante, fluidez no discurso e clareza na pronúncia.

No que se refere à análise do critério "vocabulário", um único aluno foi avaliado com o nível elementar (A1). Vale ressaltar que esse estudante, em particular, admitiu não ter se preparado para a atividade de interação, fato que pode ter prejudicado seu desempenho na atividade comunicativa, uma vez que a falta de informações para discutir o tema proposto na entrevista podia limitar o estudante a discutir apenas o que era do seu conhecimento acerca da temática ${ }^{5}$.

Outro item que compõe a avaliação da proposta refere-se à "coerência e coesão", um critério que trata da capacidade de enlaçar palavras, elementos que permitem construir uma sequência linear e conexa de informações. Os resultados com relação a esse critério apontam que a maioria dos estudantes conseguiu exprimir-se de forma articulada, além de ligar uma série de elementos curtos, distintos e simples, construindo algumas sequências

\footnotetext{
${ }^{5}$ Vale ressaltar que era um pré-requisito a realização de um estudo prévio acerca do tema, levando em conta a dinâmica planejada para a atividade de interação oral - o diálogo entre o professor chileno-estudante-estudante.
} 
lineares. Os estudantes que não se encontram no nível almejado, conseguiram comunicar algumas ideias e informações, e foram auxiliados pelo professor, a fim de exprimir aquilo que pretendiam dizer, utilizando conectores mais frequentes para expressar suas informações e interagir com os demais colegas e com o falante chileno.

Essas diferenças encontradas nas avaliações realizadas por professor e estudantes ressaltam a dificuldade em avaliar a interação oral, evidenciando a complexidade desse processo. A subjetividade é apontada por vários autores como um dos principais obstáculos na avaliação da língua oral. Para Ferraz (1994, p. 2), "aceitar a subjetividade em avaliação é ainda a forma mais eficaz de tentar controlá-la, evitando a ilusão de que a objetividade é possível e de que o aluno é aquilo que o teste mede". É preciso aceitar a subjetividade em avaliação para uma melhor aproximação da realidade.

Contudo, apesar de reconhecer a subjetividade e os desafios do processo, é possível utilizar ferramentas, como as rubricas, embasadas em critérios e descritores, que permitam auxiliar o professor, no gerenciamento dos resultados e aos estudantes, na identificação do próprio desempenho em relação à atividade.

O questionário aplicado aos estudantes também evidenciou outros resultados, como a efetividade da proposta para a avaliação da interação oral por meio da aplicação da proposta com o uso da rubrica que possibilitou a avaliação de diferentes critérios, descritores e escala de níveis, e permitiu a compreensão das expectativas do professor para cada critério avaliado.

Os estudantes destacaram como principais benefícios da proposta avaliativa: i) estudo de temas importantes e necessários para desenvolvimento da interação oral em LE; ii) realização de webconferência; iii) preparação para o uso da língua com nativos ou com pessoas de culturas diferentes; iv) prática da LE em aspectos da língua como vocabulário, pronúncia, fluência; vi) possibilidade de realizar a autoavaliação da interação oral em LE; e v) uso de tecnologias digitais na atividade, como a utilização da ferramenta Hangouts. De modo geral, os resultados reforçam as vantagens 
da utilização de uma proposta avaliativa diferenciada, que foge da tradicional realização de entrevistas, compostas por perguntas e respostas na dinâmica professor-estudante.

De acordo com os estudantes: "é relevante conhecer o próprio desenvolvimento (Estudante 1)", no entanto, "não é uma tarefa fácil por se tratar de outra língua (Estudante 3)", além "de exigir muita sinceridade, uma vez que se deve entender como elemento importante no processo de aprendizagem de um idioma (Estudante 4)".

A avaliação dos estudantes também apontou as principais dificuldades na realização da proposta: i) falta de conhecimento da ferramenta; ii) falta de experiência na realização da autoavaliação; iii) nervosismo; iv) timidez; v) obstáculo para a comunicação com um nativo; vi) e o esquecimento de algumas palavras.

Entre esses aspectos, o nervosismo também pode ser um dos problemas para a avaliação, como afirmam Barquero Dávanzo e Ureña Salazar (2015). No relato de um estudante, constatamos que a exposição real causou desconforto, sendo necessário um tempo para ser superado: "Como fue la primera vez yo no sabía como hacerlo, después relajê" (Estudante 4). Outros desafios encontrados referem-se ao nervosismo e a timidez: "Como fue notorio, yo estaba bastante nerviosa durante la entrevista. Si yo pudiera volver y corregir mis errores, enfrentaría ese desafío nuevamente, pero sin embargo menos nervioso y más segura en el hablar en la lengua estudiada (Estudante1).Dificuldades mais pontuais também foram relatadas, tais como: "hablar con un nativo sobre politica; contextualizar las palabras que debo usar, olvidar de algunas palabras" (Estudante 6).

Com base nesses resultados, ressaltamos a importância de que "o estudante tenha informação sobre seu próprio processo de aprendizagem, isto é, se está conseguindo alcançar os objetivos que se propunham" (GARCÍA GARCÍA; TERRÓN LÓPEZ; BLANCO ARCHILLA, 2010, p.291, tradução nossa). Para isso, os autores destacam a relevância em contar com uma série de instrumentos que possam auxiliar no processo avaliativo. 
Além dos desafios enfrentados pelos estudantes, também ressaltamos as principais limitações para a implementação da proposta. De acordo com a professora da turma, uma das principais dificuldades foi assegurar que o estudante realizasse o estudo prévio acerca do tema proposto, além de fomentar a participação dos estudantes na atividade. Para garantir que os estudantes se envolvessem, todos deveriam acessar as orientações deixadas no Google Classroom, e encaminhar ao professor um esboço com possíveis perguntas e respostas sobre o tema escolhido para as correções linguísticas, por e-mail e/ou WhatsApp. Dessa forma, o professor da turma podia acompanhar os estudantes, realizar feedbacks e sanar dúvidas. Outro desafio comentado refere-se à necessidade de espaços específicos para realização da proposta e de funcionamento adequado da internet.

\section{Considerações finais}

Evidenciamos uma proposta para avaliar a interação oral em LE que compreende três componentes: uma Matriz de descritores para avaliação da interação oral em LE; uma atividade com ênfase na imersão comunicativa e tecnológica; e uma rubrica para (auto)avaliação do desempenho dos estudantes, com respeito ao desenvolvimento de cinco critérios relacionados à língua: conteúdo, vocabulário, coerência e coesão, fluência e pronúncia.

Trata-se de um produto educacional que pode auxiliar no processo de avaliação dessa habilidade comunicativa e ser aplicado a outras realidades pedagógicas. Nesse sentido, pode contribuir, especialmente com os docentes que atuam em cursos de extensão e na modalidade de Cursos Livres, e enfrentam constantes desafios referentes à avaliação da interação oral em LE e identificação do nível de proficiência na língua-alvo.

Entre as principais contribuições da proposta, destacamos: i) promoção de uma atividade diferenciada em sala de aula, por intermédio do Hangouts e experiências de webconferência, ii) momento de imersão linguística, comunicativa e tecnológica, possibilitada pelo contato on-line com falante 
nativo e uso de recursos tecnológicos; iii) alteração na rotina de ensinoaprendizagem potencializando estudos autônomos e dedicação extraclasse para o desenvolvimento de pesquisas; iv) desenvolvimento de habilidades digitais, associadas ao desenvolvimento da competência comunicativa, por meio da utilização de diferentes recursos tecnológicos, tais como a plataforma Google Classroom, WhatsApp e Hangouts; e v) fomento à autoavaliação, permitindo que os aprendizes pudessem valorar suas produções na língua, identificar as principais dificuldades e compreender os avanços alcançados, com base em critérios e descritores pré-definidos.

Apesar das contribuições, a proposta também apresentou algumas limitações, tais como: a necessidade de realização de pesquisa e estudo prévio acerca do tema proposto e conhecimento do vocabulário necessário para a interação na língua; a exigência de espaços específicos para que a atividade fosse desenvolvida e a internet como condição básica para implementação da prática.

Outro aspecto que pode ser tomado como uma limitação para a aplicação da proposta leva em conta o uso da rubrica, considerando algumas das limitações apontadas por estudiosos para o uso dessa ferramenta: exigência de dedicação e supervisão por parte dos docentes (RODRÍGUEZ GALLEGO, 2012), e o tempo gasto em sua elaboração, caso necessite ser adaptada a outros contextos, com base nas características dos estudantes, níveis de ensino, e adpatção dos critérios e descritores, utilizados (MORAL MANZANARES, 2013).

Tendo em vista tais limitações, destacamos a necessidade de ampliar os estudos sobre a avaliação da habilidade oral em Língua Espanhola, com o intuito de realizar novas pesquisas sobre os principais aspectos teóricos e metodológicos que envolvem o processo de ensino, aprendizagem e avaliação, assim como adaptar a proposta criada e implementar novas experiências avaliativas da língua-alvo em outros contextos e ensino-aprendizagem. 


\section{Referências}

BARQUERO D'AVANZO; MILENA, UREÑA SALAZAR, ELVIA. Rúbricas para evaluar la competencia oral en un segundo idioma: un estudio de caso. InterSedes, São José, 16(34), 1-22. 2015. Disponível em:

http://www.scielo.sa.cr/pdf/is/v16n34/2215-2458-is-16-34-00017.pdf. Acesso em: 15 ago. 2019.

COELHO, Iandra Maria Weirich da Silva; TEIXEIRA, Wagner Barros (orgs.). Investigações e práticas de ensino-aprendizagem em centros de língas do Amazonas. Prefácio Dr. Sérgio Freire. Jundiaí: Paco Editorial, 2020.

CONSELHO DA EUROPA. Quadro Europeu Comum de Referência para as linguas: Aprendizagem, ensino, avaliação. Porto: Asa Editores. 2001.

CRESTANI, Anelise Henrich; MORAES, Anaelena Bragança; SOUZA, Ana Paula Ramos. Validação de conteúdo: clareza/pertinência, fidedignidade e consistência interna de sinais enunciativos de aquisição da linguagem. CoDAS, São Paulo, 29(4), 1-6. 2017. Disponível em: https://www.scielo.br/scielo.php?pid=S231717822017000400305\&script=sci_arttext\&tlng=pt. Acesso em: 10 ago. 2019.

ECKERT, Kleber; FROSI, Vitalina Maria. Aquisição e aprendizagem de línguas estrangeiras: princípios teóricos e conceitos-chave. Domínios de Lingu@gem, Uberlândia, 9 (1), 98-216, jul. 2015. DOI: https://doi.org/10.14393/DL17v9n1a201510 .

ESCOBAR, Cristina; NUSSBAUM, Luci. ¿Es posible evaluar la interacción oral en el aula? Marco ELE, Revista de Didáctica Español Lengua Extranjera, Valência, 10, 37-52. 2010.

FERRAZ, I. Instrumentos de avaliação: diversificar é preciso. I. E. E. (Ed.). Pensar avaliação, melhorar a aprendizagem. Lisboa: IEE. 1994. Disponível em:

http://www.dge.mec.pt/sites/default/files/Secundario/Documentos/Avaliacao/instru mentos_avaliacao.pdf. Acesso em: 10 set. 2019.

FREITAS, Luciana Maria Almeida; SOUZA, Carlos Fabiano. Trabalho docente em cursos livres de idiomas: discurso direto e a voz da hierarquia. Bakhtiniana. Revista de Estudos do Discurso, São Paulo, 13(1) 31-51, jan./abr. 2018. DOI: http://dx.doi.org/10.1590/2176-457332994.

FREITAS, Luciana Maria Almeida de. Da fábrica à sala de aula: vozes e trabalho do professor espanhol em cursos de linguas. 2010. 309 f. Tese (Doutorado em Letras Latinas) - Faculdade de Letras, Universidade Federal do Rio de Janeiro, Rio de Janeiro.

GARCÍA GARCÍA, María José; TERRÓN LÓPEZ, Ma; BLANCO ARCHILLA, Yolanda. Desarrollo de recursos docentes para la evaluación de competencias genéricas. ReVisión, Castellón, 3 (3), 17-36. 2010. Disponível em:

https://dialnet.unirioja.es/servlet/articulo?codigo=5834057. Acesso em: 20 set. 2019. 
HYMES, D. On Communicative Competence. In J. B. Pride \& J. Holmes (Eds.), Sociolinguistics (pp.269-293). Inglaterra: Penguin Books, 1972.

JETTÉ, Karine. La evaluación interaccional en la clase de ELE. MarcoELE. Revista de Didáctica Español Lengua Extranjera, Valência, 25, 1-107. 2017.

MARTÍNEZ-ROJAS, José Guillermo. Las rúbricas en la evaluación escolar: su construcción y su uso. Avances en medición, Colômbia, 6, 129-134. 2008. Disponível em: https://docplayer.es/21147749-Las-rubricas-en-la-evaluacion-escolar-suconstruccion-y-su-uso.html. Acesso em: 30 set. 2019.

MENDONÇA, Andréa Pereira; COELHO, Iandra Maria Weirich da Silva. Rubricas e suas contribuições para a avaliação de desempenho de estudantes. In: SOUZA, Ana Cláudia Ribeiro de Souza et al. Formação de Professores e Estratégias de Ensino: Perspectivas Teórico Práticas. Curitiba: Appris, 2018.

MONTEIRO, Carla et al. Avaliação da competência comunicativa oral no Ensino Básico: Um estudo exploratório. Revista portuguesa de Educação, Minho, 26(2), 111-138. 2013. DOI: https://doi.org/10.21814/rpe.3248.

MORAL MANZANARES, F. Escalas de descriptores y fiabilidad de la evaluación de la expresión e interacción orales del usuario competente. Revista Nebrija de Lingüistica Aplicada a la enseñanza de las lenguas. Madri, 13,1-6. 2013. Disponível em: https://www.nebrija.com/revista-

linguistica/files/articulosPDF/articulo_532969b19a90c.pdf. Acesso em: 05 out. 2019.

PANTOJA, L. M. ¿Evaluación en competencias? Estudios Pedagógicos 38(1), 353366. Valdivia, vol.38, n.1, pp.353-366. 2012. Disponível em:

https://scielo.conicyt.cl/scielo.php?script=sci_abstract\&pid=S0718-

07052012000100022\&lng=en\&nrm=iso\&tlng=es. Acesso em: 01 out. 2019.

QUEVEDO-CAMARGO, Gladys; GARCÍA, Lucas Henrique. Avaliação da oralidade em língua inglesa: a atribuição de notas como expressão da subjetividade do professor. Signum, Londrina, 20(3), 93-117. 2017. Disponível em:

http://www.uel.br/revistas/uel/index.php/signum/article/viewFile/25481/22644. Acesso em: 23 set. 2019.

RODRÍGUEZ GALLEGO, Margarita R. Cómo evaluar la competencia comunicativa a través de rúbricas en educación superior. Didac, Cidade do México, 60, 27-31. 2012. Disponível em: https://idus.us.es/xmlui/handle/11441/42955. Acesso em: 30 set. 2019 .

ROMÉU ESCOBAR, C. Angelina et al. El enfoque cognitivo, comunicativo y sociocultural en la enseñanza de la lengua y la literatura. La Habana: Editorial Pueblo y Educación, 2007.

SILVA, Paulo Bruno Lopes da. Práticas de expressão oral em Francês Língua Estrangeira a distância: desenvolvimento da fluência oral e da fluência digital em 
um curso on-line. 2018. 298 f. Dissertação (Mestrado em Língua e Literatura Francesa) - Universidade de São Paulo, São Paulo.

SOARES, Franciane de Araújo. Interação Oral Em Língua Espanhola: Construção de uma Proposta Avaliativa. Orientadora: Iandra Maria Weirich da Silva Coelho. 2019.114 f. Dissertação (Mestrado em Ensino Tecnológico) - Instituto Federal de Educação, Ciência e Tecnologia do Amazonas, Manaus. Disponível em: http://repositorio.ifam.edu.br/jspui/handle/4321/409. Acesso em: 29 jun. 2020.

); Franciane de Araújo; COELHO, Iandra Maria Weirich da Silva. Proposta para Avaliar a Interação Oral em Língua Espanhola: Guia Didático para Professores. Produto Educacional (Mestrado em Ensino Tecnológico), Instituto Federal de Educação, Ciência e Tecnologia do Amazonas, Manaus. Disponível em: http://repositorio.ifam.edu.br/jspui/handle/4321/413. Acesso em: 15 abr. 2020.

YIN, Robert K. Estudo de Caso: Planejamento e métodos. Porto Alegre: Bookman editora, 2015. 